\title{
SCREENING ALTERNATIVE STRUCTURES FOR PLANT CONTROL SYSTEMS
}

\section{Progress Report}

for the period October 1,1988 to September 30, 1989

J. M. Douglas and M. F. Malone

\section{Department of Chemicai Engineering \\ University of Massachusetts \\ Amherst, MA 01003}

January 1990

prepared for

THE U. S. DEPARTMENT OF ENERGY

AGREEMEIJT NO. DE-FG02-87ER13676 


\section{ABSTRACT}

This report describes progress in the development of a systematic procedure for the screening of chemical process flowsheets using control objectives in combination with economics. Progress in the last year has been in the areas of identification of rules for the screening of steady-state operability in continuous chemical processes and in the development of performance models for complex columns in distillation systems.

\section{NOTICE}

This report was prepared as an account of work sponsored by the United States Govemment. Neither the United States not the Department of Energy, nor any of their employees, nor any of their contractors, subcontractors, or their employees, makes any warranty, express or implied, or assumes any legal liability or responsibility for the accuracy, completeness, or usefulness of any information, apparatus, product or process disclosed or represents that its use would not infringe privately-owned rights. 
Conventional chemical process control focuses on the dynamic behavior of individual units and often ignores interactions in the process. An alternative approach is to start by considering the effects of persistent disturbances (from the connections to the environment) on the steady-state performance of the plant. If there is a poor steady state response, then the flowsheet can be modified and when we have determined a few economically interesting alternatives at the conceptual design stage, we can use the estimated response to disturbances as an additional screening tool for selecting the best flowsheet.

It is important recognize the difference between design and control studies; a result shown in our previous work (c.f., Douglas, 1988) is that it is never desirable to operate a chemical process at the optimum steady-state design conditions. As a result, we generally want to operate some of the equipment at constraints where the usual linear dynamic models used in control studies will not be applicable. We generally find that control schemes that minimize the use of excess raw materials are more desirable than those that seek to minimize energy use alone (e.g., Terrill and Douglas, 1987) and the interactions between energy integration and design can be quite important.

There are many examples where continuous chemical processes encounter operability problems on account of the presence of trace components. In some cases, there are inerts in the feed(s) that accumulate in recycle streams; in other cases, the trace components are produced as byproducts in the process. In the common case where distillation is used for the liquid separations, we have 
developed the following rules to test for operability in continuous plants.

First, we make a list of all of the components in every reaction and in every feed stream and order the list by normal boiling point. Next, we specify thie destination of each component leaving the reactor using the rules developed by Douglas (1988). This gives a classification of each component as a exit or a recycle component. We can test the list to discover operability problems as follows. (1) If two adjacent component are recycled, trace components boiling between the two will accumulate. (2) If the first or last component in the list is recycled, trace components (lighter or heavier, respectively) will accumulate. (3) If a recycled component is a neighbor to a product, then any trace component boiiing between the two must leave with the product. In the first two cases, an additional exit point is needed to insure operability, while extra capacity of the equipmeni in the recycle loop may be required for the third case.

We have also developed procedures for estimating the necessary overdesign of distillation systems to accommodate feed rate or composition changes that are found at the extremes of utility temperatures. The overdesign of reactors to insure that the heat transfer capability is adequate for the range of anticipated disturbances has also been studied.

A more detailed discussion of the points above with examples is given by Douglas (1989).

After screening of steady-state economics a: $d$ process operability, reduced order performance models for the candidate flowsheets are needed for further 
screening. We have also developed collocation models for distillation systems, including complex columns. Rapid estimates of the steady-state gain matrix and its singular value decomposition, the condition number for the model, the relative gain array, and various disturbance condition numbers can be made without the need for detailed simulation. We have screened a variety of control schemes for the separation of multicomponent mixtures in sidestream columns, focusing on the influence of the design conditions. The approach has also been used to study selected nonideal binary mixtures. More detailed discussion and examples can be found in DeGuiran and Malone (1989a,b).

\section{ADMINISTRATIVE}

The principal investigators have complied with the basic terms of the Agreement. Each of the investigators has devoted $15 \%$ of time during the academic year and $33.3 \%$ of time during the summer to this project and the same percentage of time is expected to be devoted during the remainder of the project. 


\section{LITERATURE CITED}

M. DeGuiran and M. F. Malone, "Screening Steady-State Control Structures for Distillation System Design," Proceedings of the Seventh Symposium on Energy Engineering Sciences. Nonlinear Mechanics and Mechanical Systems, Argonne National Laboratory, Argonne, ILL, June 19-21, 1989a. pp. 121-28.

M. DeGuiran and M. F. Malone, "Steady-State Control Considerations for Distillation System Designs," paper 167Bm, AlChE Annual Meeting, San Francisco, CA, November, 1989b.

J. M. Douglas, Conceptual Design of Chemical Processes, McGraw-Hill, NY (1988).

J. M. Douglas, "Modifying Process Flowsheets to Improve Process Control," Proceedings of the Seventh Symposium on Energy Engineering Sciences. Nonlinear Mechanics and Mechanical Systems, Argonne National Laboratory, Argonne, ILL, June 19-21, 1989. pp. 114-20.

D. L. Terrill and J. M. Douglas, Industrial and Engineering Chemistry Research, 26, 685 (1987). 

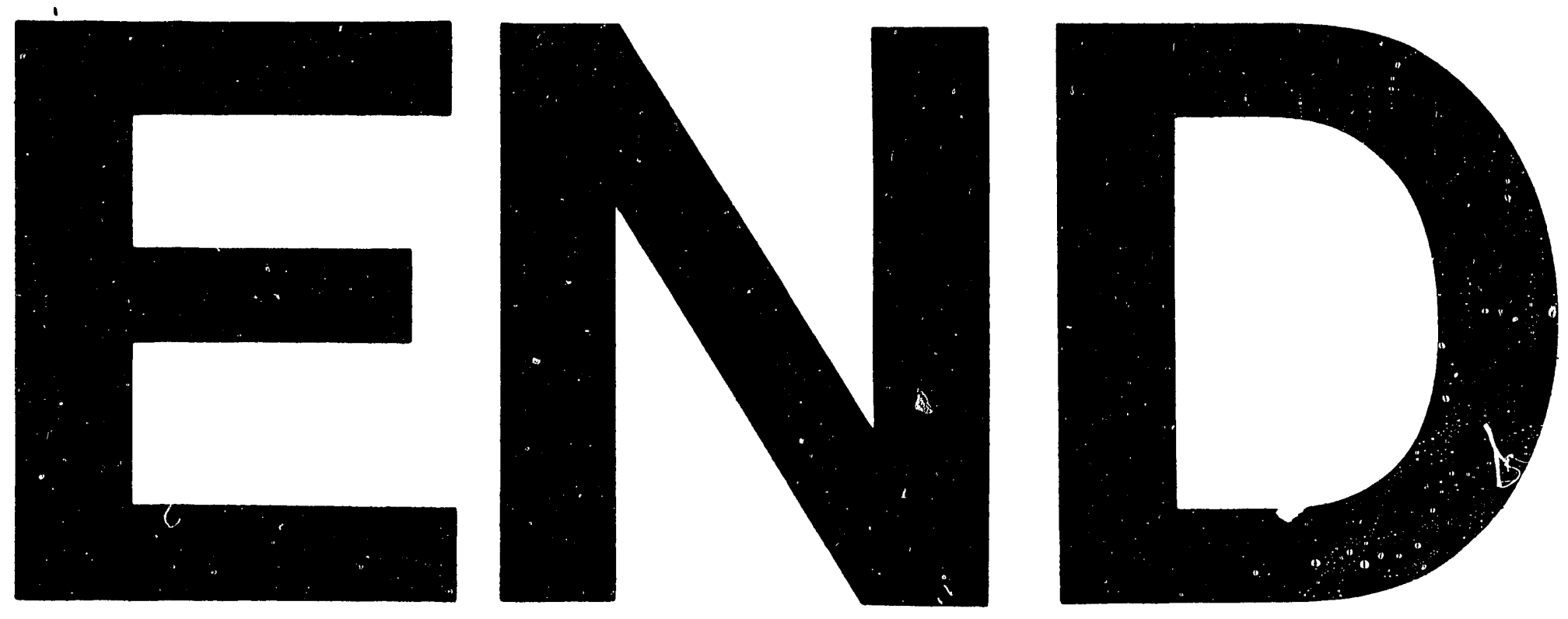

.

$+4$
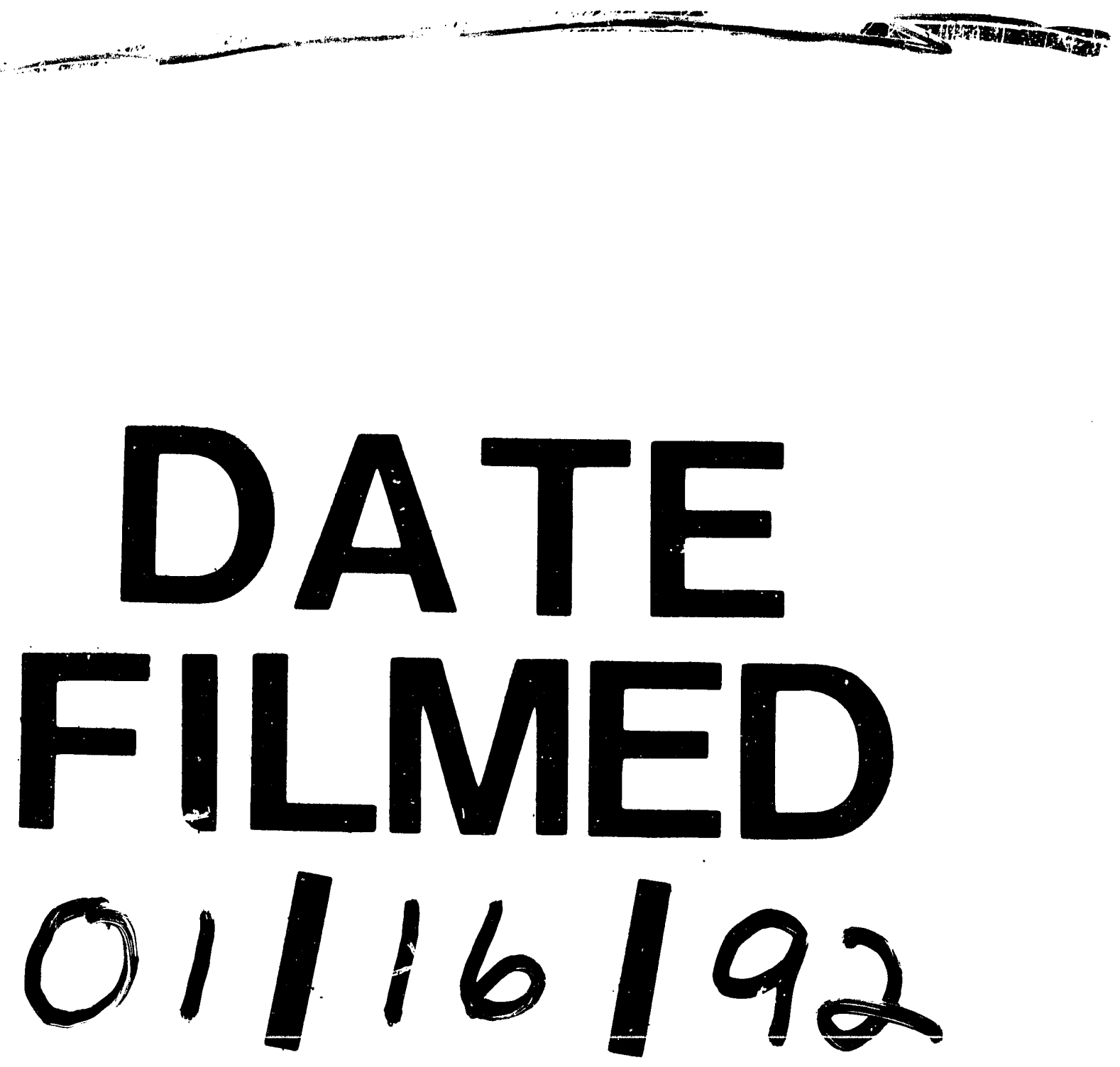
